\title{
Synthesis of Ru(IV) modified Pt/C electrocatalyst and its application for enhanced methanol electrooxidation
}

\author{
Shaojun Li, Junming Chen ${ }^{*}$ and Lei Bai ${ }^{*}$ \\ College of Chemistry and Materials Engineering, Anhui Science and Technology University, Bengbu, \\ Anhui, China, 233030 \\ *E-mail: cjmmap@163.com, baileiwj2014@163.com
}

Received: 30 Octeober 2021 / Accepted: 13 December 2021 / Published: 5 January 2022

\begin{abstract}
Commercial Pt/C was modified with $\mathrm{Ru}$ (IV) species via the hydrolysis of Ruthenium (III) nitrosyl nitrate under a hydrothermal condition. It was revealed that the Pt nanoparticles were surrounded by $\mathrm{Ru}$ (IV) species and the presence of Ru (IV) species modified the electronic structure, which lowed the binding energy of $\mathrm{Pt}$ atoms. The results from the methanol electrooxidation suggested that the current intensity was increased and at the same time, the onset potential was decreased largely in the presence of $\mathrm{Ru}(\mathrm{IV})$ species modified $\mathrm{Pt} / \mathrm{C}$, which demonstrated the fact that the $\mathrm{Ru}(\mathrm{IV}$ ) species could activate the water molecules to provide the $\mathrm{OH}^{*}$ to remove the $\mathrm{CO}_{\text {ads }}$ at low potential.
\end{abstract}

Keywords: Commercial Pt/C; Ru (IV) species; chemical modification; catalytic electrooxidation

\section{FULL TEXT}

(C) 2022 The Authors. Published by ESG (www.electrochemsci.org). This article is an open access article distributed under the terms and conditions of the Creative Commons Attribution license (http://creativecommons.org/licenses/by/4.0/). 